\title{
RESPUESTAS A COMENTARIOS "SUPERANDO LAS DICOTOMÍAS: EL QHAPAQ ÑAN COMO EJEMPLO DEL PATRIMONIO COMO PROCESO SOCIAL"
}

\author{
Giancarlo Marcone Flores ${ }^{1}$
}

Antes de comenzar quisiera agradecer a los colegas que aceptaron hacer comentarios a mi artículo "Superando las dicotomías: el Qhapaq Ñan como ejemplo del patrimonio como proceso social". En especial porque no es una tarea fácil comentar un artículo que hace directa mención, de manera crítica, al trabajo de uno. A pesar de esto, los comentaristas se involucran con el argumento de fondo del artículo y hacen, en su mayoría, comentarios que alimentan el desarrollo del argumento que sustento.

El artículo presentado a Chungara Revista de Antropología Chilena es más que el análisis a los artículos de diversos autores. El texto presenta un análisis crítico de estos trabajos con el fin de graficar una posición que en los últimos años se está volviendo predominante en la academia. En constraste a lo que sostiene Gnecco, en mi opinión, esta posición no tiene nada de marginal. Una posición que pone el dedo en el problema, cuestiona la patrimonialización pero, a mi entender, no ofrece alternativas. Además, no avanza en la necesaria reconceptualización del patrimonio que la crítica de los últimos 20 años ha hecho ver que es $\tan$ necesaria. Es en este aspecto que considero que el artículo presentado intenta hacer su mayor aporte.

El artículo no tiene la intención de defender lo indefendible. Este reconoce explícitamente que el Qhapaq Nan ha sido, en su gran mayoría, un proyecto de arriba hacia abajo, una iniciativa estatal. Además, reconoce que el discurso patrimonial tradicional ha sido fuente de exclusión y enajenación de las poblaciones circundantes al mismo. Hasta ese punto creo que todos estamos de acuerdo. Lo que pregunta el artículo es: ¿Qué sigue después de reconocer este hecho? ¿Cuál va ser nuestra relación con el patrimonio? ¿Existe la posibilidad de gestionarlo de manera no hegemónica o debemos abandonarlo del todo? ¿No hay valor en él por el hecho de haber sido concebido de manera asimétrica en su comienzo?
El artículo propone que la solución está en la gente, en devolverle la agencia a la gente en esta discusión. Soltar poder y aceptar que no sabemos mucho de lo que la gente quiere o espera del patrimonio y cómo se relaciona con los procesos de patrimonialización. En mi experiencia, con todo derecho, las personas tienen actitudes cambiantes de acuerdo a su conveniencia. El patrimonio pierde valoración, o la gana o cambia de significado de acuerdo al tiempo y al contexto. La disonancia sobre la que habla Gnecco está en los actores alrededor del patrimonio, no solo en nosotros los académicos, y nuestra misión es fomentar esta disonancia. Sin esta perspectiva, orientada hacia la gente, la crítica patrimonial corre el riesgo de convertirse en un discurso hegemónico más que hace poco por cambiar las prácticas patrimoniales tradicionales.

Una posición de buenos versus malos en la discusión académica, claramente, nos impide aceptar esta perspectiva. En este artículo sostengo una discusión que plantea una dicotomía entre Estadomodernidad-patrimonializador versus Comunidades, claramente opuestas a la modernidad en defensa de sus tradiciones. Una dicotomía que me gustaría poder superar. Además, esta nos pone en riesgo de asumir que porque estamos denunciando los procesos de patrimonialización tradicional entonces representamos las opiniones de las comunidades campesinas o poblaciones locales.

En ningún momento sostengo que los autores quieran intencionalmente hablar en nombre de las comunidades, sino que es un potencial riesgo que corremos. Korstanje y Losson en sus comentarios rechazan la intención o el resultado de hablar por las comunidades. Gnecco, en cambio, afirma y justifica el hecho de que debemos hablar por ellas. Personalmente, el tema de la representatividad siempre me genera cuestionamientos, cómo evitamos construir

\footnotetext{
${ }^{1}$ Universidad de Ingeniería y Tecnología, Lima, Perú. gmarcone@utec.edu.pe 
lo que comúnmente llamamos las torres de marfil académicas que terminan teniendo poca presencia e impacto en la sociedad en general.

Korstanje y Losson niegan en sus comentarios la existencia de tal dicotomía. Sin embargo, Gnecco en sus comentarios reconstruye exactamente esta dicotomía, poniendo la discusión en términos de buenos y de malos. El hecho de asumir una postura crítica hacia sus argumentos, o pensar que el patrimonio sí tiene algún nivel de representación o utilidad en la gente, inmediatamente me convierte en un agente patrimonial representante de los poderes gubernamentales que solo quiere invalidar los artículos que atacan y quieren detener las "nuevas" fuerzas de cambio que representa su trabajo. !Qué ilusión! La postura crítica respecto a la manipulación del Estado sobre el patrimonio, que cuestiona la utilidad del mismo e inclusive piensa que es un mecanismo de dominación por parte de los estados, es una discusión de larga data que más bien se está convirtiendo en un lugar común en la academia latinoamericana.

Desde el momento que decidí aceptar la invitación de la revista Chungara para hacer el presente un artículo de discusión sabía que no estaría exento de críticas. Muchas de ellas, como es el caso, estarían basadas en el hecho de haber trabajado en el Proyecto Qhapaq Ñan peruano. Sin embargo, era importante para mí discutir estos temas y mostrar la búsqueda de conceptos que dirigieron mis acciones durante los años 2013-2018. Acciones que buscaron, sobre todo, alejarse del manejo tradicional del patrimonio y muchas de las prácticas que hasta ese momento el Proyecto Qhapaq Nan-Sede Nacional tenía. Losson hace un interesante punto en este aspecto sobre la posición del autor con respecto al sujeto sobre el que está escribiendo.

Losson sugiere que mis cuestionamientos van a la academia en general, que de alguna manera invalido la discusión académica. Nada más distante en mi intención, reconozco la influencia del todo el trabajo previo en mi intento de conceptualización del patrimonio y no renuncio a la pretensión de darle profundidad conceptual a una gestión como funcionario público. Justamente es el llegar desde la academia a la gestión lo que me hizo cuestionar algunas (no todas) de las posturas académicas imperantes, quizás en busca de hacer sentido de mi actividad.

Justamente después de leer la bibliografía, aproximarme a la gestión del patrimonio y encontrar una serie de conceptos que no se ajustaban a la realidad, como por ejemplo las expectativas y actitudes de la gente con respecto al Qhapaq Ñan y como variaban, fue lo que me llevó a buscar cómo entender lo que pasaba. Por ello comparto mi conceptualización del problema, de la brecha entre lo que encuentro publicado con la práctica, y discuto lo que yo pienso es una solución conceptual y programáticamente.

Estoy convencido que la discusión teórica en ambientes académicos debe alimentar las experiencias prácticas. Por ello escribo este artículo y luego acepto someterlo a discusión. En ese sentido no creo que mi artículo pueda dejar de ser ideológico, como sugiere Korstanje, ni lo intento. Lo que puedo pretender es mostrar los criterios técnicos que fundamentan una postura.

Definitivamente soy ambas cosas, académico por un lado y gestor por el otro, aunque prefiero pensar que soy más académico que gestor. Si bien ya no trabajo en el Ministerio de Cultura ni en el proyecto Qhapaq Nan, claramente tuve responsabilidad sobre la forma que este tomó, al menos en el Perú, desde el 2013 al 2018. Responsabilidad por las cosas que pudimos cambiar en ese tiempo y las cosas que no pudimos cambiar. El artículo no pretendió, ni pretende, hablar desde una posición oficial o justificar alguna acción u otra. Más bien, desde una búsqueda personal, mostrar una alineación entre la teoría que guio mis acciones y la práctica de hacerlas reales.

Pero, como sabemos, ninguno de nosotros puede ser realmente objetivo. Creo que el hecho de haber sido funcionario no invalida mi opinión, como tampoco invalida, sino enriquece sus respectivos artículos el hecho de que Losson fuera Director Cultural de la Alianza Francesa en Lima y haya sido tratado descortésmente por los funcionarios del Proyecto Qhapaq Ñan de su momento o que Korstanje haya participado, aunque brevemente, en la elaboración del expediente de nominación en Argentina. Es esta experiencia la que hace los estudios más interesantes. En caso contrario solo Bianchi, quien no está involucrada en el Qhapaq Ñan directamente, podría opinar. Curiosamente de todos los comentaristas es Bianchi la que rescata el valor y la pertinencia de la discusión que el artículo intenta hacer.

Obviamente soy ideológicamente optimista, creo que a pesar de la supervivencia de las prácticas verticales y de la supervivencia de la visión tradicional del mismo, el patrimonio sí puede ser vehículo de cambio y de inclusión. No es una tarea fácil y, como dicen los colegas, muchas veces las buenas intenciones se ven truncadas por el mismo Estado. A veces el problema viene desde la conceptualización de uno mismo. Es por ello que debemos seguir discutiendo nuestras concepciones de patrimonio y nuestros intentos y fracasos. Ojalá los gestores se involucren en los debates académicos, se alimenten de ellos e intenten moverse más allá de los mismos. 